\title{
Elevated circulating magnesium levels in patients with Parkinson's disease: a meta-analysis
}

This article was published in the following Dove Press journal:

Neuropsychiatric Disease and Treatment

\author{
Xin Jin' \\ Ming-Yan Liu² \\ Dong-Fang Zhang' \\ Hua $\mathrm{Gao}^{3}$ \\ Min-Jie Wei ${ }^{2,4}$ \\ 'School of Pharmacy, Department \\ of Pharmacognosy, China Medical \\ University, Shenyang, Liaoning, China; \\ ${ }^{2}$ School of Pharmacy, Department \\ of Pharmacology, China Medical \\ University, Shenyang, Liaoning, China; \\ ${ }^{3}$ Division of Pharmacology Laboratory, \\ National Institutes for Food and Drug \\ Control, Beijing, China; ${ }^{4}$ Liaoning Key \\ Laboratory of Molecular Targeted \\ Anti-Tumor Drug Development and \\ Evaluation, Shenyang, Liaoning, China
}

Correspondence: Min-Jie Wei School of Pharmacy, Department of Pharmacology, China Medical University, No 77 of Puhe Road, Shenyang North New Area, Shenyang, Liaoning II 0122 , China

Tel +862431939448

Emailminjie_wei@I63.com
Background: The association between circulating magnesium $(\mathrm{Mg})$ and Parkinson's disease (PD) remains ambiguous and controversial. Thus, a meta-analysis was conducted to evaluate the circulating Mg levels in PD patients and to clarify whether high circulating Mg levels should be considered as a potential risk factor for PD.

Methods: In this study, 17 case-control published studies were selected in our meta-analysis by searching the electronic databases of Web of Science, PubMed, and China National Knowledge Infrastructure (CNKI) before June 1, 2018. Overall, 848 PD cases and 784 healthy controls (HC), 1,023 PD cases and $911 \mathrm{HC}$, and $180 \mathrm{PD}$ cases and $144 \mathrm{HC}$ met the inclusion criteria for this study Mg levels in serum, peripheral blood, and cerebrospinal fluid (CSF), respectively. Standardized mean difference (SMD) in random-effects model and 95\% CI were used to assess the correlation strength through the comparison of the two groups.

Results: Meta-analysis showed that the serum Mg levels in PD cases were significantly higher than those in $\mathrm{HC}$ individuals ( $\mathrm{SMD}=1.09,95 \% \mathrm{CI}=0.52,1.66$ ). Furthermore, this result was further confirmed by the combined analysis of serum and whole blood studies together ( $\mathrm{SMD}=0.64$, $95 \% \mathrm{CI}=0.10,1.19)$. In addition, the higher CSF Mg levels in patients of PD were observed in comparison with normal range ( $\mathrm{SMD}=0.55,95 \% \mathrm{CI}=0.21,0.88)$. However, this data did not further discuss and analyze because of the smaller sample size of CSF studies.

Conclusion: Our findings supported the notion that the increase of circulating $\mathrm{Mg}$ levels appears in the patients with PD.

Keywords: magnesium, serum, peripheral blood, CSF, Parkinson's disease, meta-analysis

\section{Introduction}

Parkinson's disease (PD), the second most frequent neurodegenerative disorder of aging, is characterized by the dopamine reduction in striatal and progressive and selective loss of dopaminergic neurons in substantia nigra caused by unknown etiopathogenesis. ${ }^{1,2}$ It affects typical motor function including muscle rigidity, abnormal posture, bradykinesia, resting tremor, and other cognitive impairments, not only affecting the life quality of patients but also increasing the society burden. ${ }^{3}$ As we know, PD is a multifactorial disorder, many risk factors, including lifestyle, environmental factors, and micronutrients disturbances are involved in the occurrence and development of PD. ${ }^{4,5}$ Compelling evidences suggest that genetic mutations in $\alpha$-synuclein, Parkin, $P I N K, L R R K 2$, and other genes are also key factors to induce the PD, accounting for almost $10 \%$ of PD cases. ${ }^{6-8}$ In addition, the rest of PD patients caused by unexplained reason are usually rare and sporadic.

Metal homeostasis plays an important role in biological processes involved in signal transduction, cell respiration, metalloproteinase activity, and other physiological processions because of their ability to accept or donate electrons. ${ }^{9,10}$ However, the imbalance of 
metal homeostasis in brain, such as zinc, copper, manganese, or iron, also had potentially dangers for the onset and progression of neurodegenerative diseases, including PD. ${ }^{11,12}$ For instance, metals could catalyze the formation of reactive oxygen species, which caused oxidative stress leading to the death of dopaminergic neurons. ${ }^{13}$ In addition, metals even at low concentrations also could readily foster the oligomerization and aggregation of $\alpha$-synuclein associated with the pathophysiology of PD. ${ }^{14,15}$ Therefore, it is meaningful to understand the relation with metal homeostasis and PD for developing an effective preventive targeting strategy for PD.

Magnesium ( $\mathrm{Mg}$ ) is the most abundant divalent cation in human cells. ${ }^{16}$ In central nervous system (CNS), as a cofactor for various key enzymes, $\mathrm{Mg}$ is considered indispensable for a wide variety of neural functions, including energy production, neuromuscular conduction, and neurotransmitter release. ${ }^{17,18}$ Disturbances in $\mathrm{Mg}$ homeostasis have been implicated in a broad spectrum of neurodegenerative disorders of aging, including PD and Alzheimer's disease. ${ }^{19,20}$ Numerous studies pointed out the possible role of $\mathrm{Mg}$ levels in patients with $\mathrm{PD}$, but the conclusions were ambiguous and inconsistent. Several studies have shown that systemic $\mathrm{Mg}$ levels were reduced in PD patients compared with healthy controls (HC). ${ }^{21-23}$ In contrast, other articles reported a considerably higher $\mathrm{Mg}$ levels in PD patients. ${ }^{24-27}$ Also, a few studies probably tended no statistical difference in $\mathrm{Mg}$ levels between PD patients and healthy populations. ${ }^{28,29}$

Thus, we conducted the meta-analysis to comprehensively assess the serum, peripheral blood, and cerebrospinal fluid (CSF) levels of $\mathrm{Mg}$ variations in patients with PD compared with healthy cases and to provide additional insights into the maintenance for a healthy nutritional status and the prevention of PD.

\section{Methods}

\section{Search strategy}

This meta-analysis fulfilled the Preferred Reporting Items for Systematic reviews and Meta-Analyses (PRISMA) guidelines and the Cochrane Collaboration definition of both terms. ${ }^{30,31}$ We primarily searched relevant literature from Web of Science, PubMed, and China National Knowledge Infrastructure (CNKI) before June 1, 2018. The subject terms included a combination of key words, such as "magnesium" and "Parkinson's disease", "Parkinson", "serum", "blood”, "plasma", "CSF”, "metals", or "trace element" without any language limits. Also, other potentially missing relevant studies were further supplemented by handsearching the references of included articles.

\section{Inclusion criteria}

Eligible publication for inclusion in the current meta-analysis simultaneously followed the following criteria: 1) casecontrol study design; 2) human study with PD and HC groups; and 3) studies with sample size and $\mathrm{Mg}$ concentration in serum, blood, or CSF in cases and controls. Exclusion criteria are as follows: 1) abstract, letter, review, editorials, or case reports; 2) repeated data; 3) animal studies; 4) studies without numerical data of $\mathrm{Mg}$ concentration; and 5) studies without $\mathrm{Mg}$ concentration for $\mathrm{HC}$.

\section{Data extraction}

Both authors (XJ and D-F Z) independently completed the data extraction from text, tables, and figures. Data information includes first author, publication year, country, $\mathrm{Mg}$ concentration, case number, mean age, sample source, percentage of female, analysis method, duration of PD, and other study characteristics. If available, $\mathrm{Mg}$ concentration were expressed with mean $\pm \mathrm{SD}$, otherwise, estimated data from the median and range. All underlying units of $\mathrm{Mg}$ concentration varied with different studies were converted to $\mathrm{mg} / \mathrm{L}$.

\section{Statistical analyses}

The standardized mean difference (SMD) and 95\% CI were invoked as the strength of the association between $\mathrm{Mg}$ concentrations and PD risk. The value of $I^{2}$ was used to estimate the proportion of total variation attributable across study, with values $>75 \%$ indicative of significant heterogeneity between studies. ${ }^{32}$ The random-effects model was selected if $I^{2}$ value $>50 \%$, otherwise, the fixed-effects model was adopted. ${ }^{33}$ Subgroup analyses stratified by the locations and analytic methods were conducted to clarify the possible sources of between-study heterogeneity. Meta-regression analysis was employed to investigate the potentially important covariates that might affect between-study heterogeneity. ${ }^{34}$ Sensitivity analysis was used to examine whether the pooled SMD was markedly influenced by the significant difference of individual studies. ${ }^{35}$ Egger's test was used to assess publication bias comparing the effect sizes with their standard error. ${ }^{36}$ Cumulative meta-analysis was established to evaluate the temporal effect. All statistical analyses were performed using STATA 12.0 (StataCorp LP, College Station, TX, USA). Two-tailed $P$-value $<0.05$ was considered as statistically significant.

\section{Results}

\section{Characteristics of eligible studies}

A total of 380 potential articles matched the inclusion after preliminary search from the Web of Science, PubMed, CNKI, 




Figure I Meta-analysis flow diagram of the study search strategy.

and other relevant databases. After further screening, 17 final epidemiological studies were finally enrolled in current study (a total of 1,203 PD cases and 1,055 HC). The strategy of study search was provided in Figure 1.

The sample sizes of PD patients ranged from 19 to 250 . The average age of PD cases ranged from 57.6 to 65.7 years old. The percentage of female patients ranged from $7.7 \%$ to $55.0 \%$. Methods of $\mathrm{Mg}$ concentration analysis consisted of the atomic absorption spectrometry, inductively coupled plasma-atomic emission spectrometry, inductively coupled plasma-mass spectrometry (ICP-MS), inductively coupled plasma optical emission spectrometry (ICP-OES), and colorimetry. The geographic populations were European, American, Asian, and African, respectively. The detailed characteristics were summarized in Table 1.

\section{Meta-analysis of serum $\mathrm{Mg}$ levels between $\mathrm{PD}$ patients and $\mathrm{HC}$ subjects}

The overall data from 12 articles compared the serum $\mathrm{Mg}$ levels between PD patients and $\mathrm{HC}$ subjects in a randomeffects model because significant heterogeneity $\left(I^{2}=95.6 \%\right.$, $P=0.000)$ was discovered across these studies. The pooled sample size encompassed a total of 1,632 subjects including $848 \mathrm{PD}$ cases and $784 \mathrm{HC}$ subjects. The results demonstrated that serum Mg levels in PD patients were significantly higher than those in $\mathrm{HC}$ subjects ( $\mathrm{SMD}=1.09,95 \% \mathrm{CI}=0.52$, 1.66; Figure 2). Subgroup analysis accounting for location disclosed that the $\mathrm{Mg}$ levels increased in $\mathrm{PD}$ patients in Asian populations $(\mathrm{SMD}=2.22,95 \% \mathrm{CI}=0.82,3.63 ; P$ for $\mathrm{Z}=0.002$ ) and African populations ( $\mathrm{SMD}=1.18,95 \% \mathrm{CI}=0.80,1.55$; $P$ for $\mathrm{Z}=0.000$ ). In addition, the subgroup analysis stratified by analysis methods showed that a similar pattern in ICP-MS/ ICP-AES (SMD $=1.55,95 \% \mathrm{CI}=0.54,2.57$; $P$ for $\mathrm{Z}=0.003$ ). However, neither the location nor the analysis method contributed to the source of heterogeneity (Table 2).

Meta-regression found that the duration, average age, and gender of PD patients had no influences on between-study heterogeneity (Table 3). Sensitivity analysis showed that Ahmed and Santosh's study has an excessive influence on the outcome $;^{53}$ however, after the exclusion of this study, the statistical significance of the combined SMD was not unduly changed, indicating the robustness of the results. Cumulative meta-analysis revealed that no temporal effect affected the overall analysis results. Moreover, Egger's test detected no publication bias in all included studies $(P=0.054)$ and visual observation of the funnel plot also revealed symmetrical approximately.

\section{Meta-analysis of peripheral blood $\mathrm{Mg}$ levels between PD patients and HC subjects}

We further constructed a combined analysis of $\mathrm{Mg}$ serum and blood levels to evaluate $\mathrm{Mg}$ levels in peripheral blood. Fourteen articles were collected with a pooled sample size 
Table I Characteristics of the included studies in this meta-analysis (arranged by publication time)

\begin{tabular}{|c|c|c|c|c|c|c|c|c|c|c|c|c|}
\hline \multirow[t]{2}{*}{ First author } & \multirow[t]{2}{*}{ Year } & \multirow[t]{2}{*}{ Country } & \multirow[t]{2}{*}{$\begin{array}{l}\text { Analysis } \\
\text { method }\end{array}$} & \multicolumn{2}{|c|}{$\begin{array}{l}\text { Sample } \\
\text { size }\end{array}$} & \multicolumn{2}{|c|}{$\begin{array}{l}\text { Magnesium } \\
\text { concentration } \\
(\mathrm{mg} / \mathrm{L})\end{array}$} & \multicolumn{2}{|c|}{ Age (years) } & \multicolumn{2}{|c|}{$\begin{array}{l}\text { Gender } \\
\text { (\% female) }\end{array}$} & \multirow{2}{*}{$\begin{array}{l}\begin{array}{l}\text { Duration } \\
\text { of disease }\end{array} \\
\text { PD }\end{array}$} \\
\hline & & & & PD & $\mathrm{HC}$ & PD & HC & PD & HC & PD & HC & \\
\hline \multicolumn{13}{|l|}{ Serum } \\
\hline Schwab RS ${ }^{28}$ & 1964 & USA & Colorimetry & 75 & 34 & $20.9 \pm 2.8$ & $20.7 \pm 1.9$ & NR & NR & NR & NR & NR \\
\hline Luo PY50 & 1987 & China & AAS & 30 & 20 & $35.6 \pm 3.5$ & $34.1 \pm 34.3$ & $61.5 \pm 8.4$ & NR & 30.0 & NR & NR \\
\hline Forte $\mathrm{G}^{24}$ & 2004 & Italy & ICP-AES & 26 & 13 & $19.2 \pm 1.8^{*}$ & $17.5 \pm 1.3$ & $64.9 \pm 10.8$ & $63.8 \pm 13.7$ & 7.7 & 53.8 & $4.8 \pm 3.8$ \\
\hline Hegde $M L^{51}$ & 2004 & India & ICP-AES & 52 & 25 & $25.5 \pm 2.2$ & $21.9 \pm 2.2$ & $58.2 \pm 4.7$ & $55.4 \pm 6.4$ & 46.2 & 48.0 & $4.8 \pm 2.5$ \\
\hline Forte $\mathrm{G}^{25}$ & 2005 & Italy & ICP-AES & 71 & 44 & $19.0 \pm 3.3^{*}$ & $17.2 \pm 1.8$ & $65.5 \pm 9.4$ & $51.9 \pm 4.0$ & 25.4 & 25.0 & $4.6 \pm 4.5$ \\
\hline Sanjay Pande $\mathrm{MB}^{52}$ & 2005 & India & ICP-AES & 50 & 25 & $25.5 \pm 2.2$ & $21.8 \pm 2.2$ & NR & NR & NR & NR & NR \\
\hline Bocca B26 & 2006 & Italy & ICP-AES & 91 & 18 & $31.7 \pm 4.7^{*}$ & $26.5 \pm 4.8$ & $65.5 \pm 9.7$ & $63.3 \pm 13.8$ & 29.7 & 44.4 & $4.6 \pm 4.1$ \\
\hline Alimonti $A^{23}$ & 2007 & Italy & ICP-AES & 71 & 124 & $17.4 \pm 1.9$ & $18.9 \pm 3.2$ & $65.5 \pm 9.4$ & $44.8 \pm 12.7$ & 25.4 & 34.7 & $4.6 \pm 4.5$ \\
\hline Gellein $K^{22}$ & 2008 & Norway & ICP-MS & 19 & 99 & $20.7 \pm 2.5$ & $21.4 \pm 3.0$ & $61.9 \pm 9.5$ & NR & 52.6 & 51.5 & $7.7 \pm 2.3$ \\
\hline Ahmed SS ${ }^{53}$ & 2010 & India & ICP-AES & 45 & 42 & $20.1 \pm 0.4 *$ & $17.5 \pm 0.2$ & $57.6 \pm 9.1$ & $55.6 \pm 3.3$ & 42.2 & 40.5 & NR \\
\hline Ogunrin $\mathrm{AO}^{54}$ & 2013 & Nigeria & AAS & 68 & 60 & $41.3 \pm 15.8^{*}$ & $25.0 \pm 11.2$ & $65.7 \pm 7.3$ & $61.5 \pm 8.3$ & 32.4 & 36.7 & NR \\
\hline Sanyal $]^{29}$ & 2016 & India & AAS & 250 & 280 & $20.4 \pm 1.2 *$ & $19.9 \pm 1.5$ & $57.9 \pm 12.1$ & $56.4 \pm 9.7$ & 35.2 & 34.6 & $4.9 \pm 3.0$ \\
\hline \multicolumn{13}{|l|}{ Blood } \\
\hline Barbeau $A^{21}$ & 1963 & USA & Colorimetry & 28 & 20 & $15.8 \pm 2.2$ & $22.5 \pm 4.9$ & NR & NR & NR & NR & NR \\
\hline Forte $\mathrm{G}^{24}$ & 2004 & Italy & ICP-AES & 26 & 13 & $27.9 \pm 7.0^{*}$ & $24.0 \pm 2.4$ & $64.9 \pm 10.8$ & $63.8 \pm 13.7$ & 7.7 & 53.8 & $4.8 \pm 3.8$ \\
\hline Forte $\mathrm{G}^{25}$ & 2005 & Italy & ICP-AES & 71 & 44 & $31.4 \pm 4.7$ & $40.2 \pm 5.0$ & $65.5 \pm 9.4$ & $51.9 \pm 4.0$ & 25.4 & 25.0 & $4.6 \pm 4.5$ \\
\hline Feng $J^{55}$ & 2012 & China & AAS & 50 & 50 & $46.2 \pm 6.8$ & $46.4 \pm 8.5$ & $62.7 \pm 14.1$ & $61.4 \pm 11.8$ & 40.0 & 40.0 & NR \\
\hline \multicolumn{13}{|l|}{ CSF } \\
\hline Forte $\mathrm{G}^{24}$ & 2004 & Italy & ICP-AES & 26 & 13 & $20.9 \pm 2.0$ & $21.2 \pm 3.2$ & $64.9 \pm 10.8$ & $63.8 \pm 13.7$ & 7.7 & 53.8 & $4.8 \pm 3.8$ \\
\hline Alimonti $A^{56}$ & 2007 & Italy & ICP-AES & 42 & 20 & $23.7 \pm 4.3$ & $21.9 \pm 3.5$ & $64.5 \pm 10.7$ & $66.2 \pm 14.7$ & 14.3 & 15.0 & $4.9 \pm 4.3$ \\
\hline Hozumi I ${ }^{57}$ & 2011 & Japan & ICP-MS & 20 & 15 & $31.6 \pm 3.6$ & $29.6 \pm 6.5$ & NR & NR & 55.0 & 60.0 & NR \\
\hline Sanyal $]^{29}$ & 2016 & India & AAS & 50 & 60 & $25.3 \pm 3.4 *$ & $22.7 \pm 2.4$ & $58.7 \pm 12.4$ & $60.1 \pm 10.4$ & 32.0 & 30.0 & $3.8 \pm 2.3$ \\
\hline Maass $\mathrm{F}^{27}$ & 2018 & Germany & ICP-OES & 36 & 42 & $22.0 \pm 1.3^{*}$ & $21.0 \pm 1.2$ & $67.0 \pm 11.0$ & $65.5 \pm 13.1$ & 50.0 & 42.9 & $5.0 \pm 5.5$ \\
\hline
\end{tabular}

Notes: $P$-value $<0.05$ was considered as statistical significance, mean \pm SD. $* P<0.05$.

Abbreviations: AAS, atomic absorption spectrometry; CSF, cerebrospinal fluid; HC, healthy control; ICP-AES, inductively coupled plasma-atomic emission spectrometer; ICP-MS, inductively coupled plasma-mass spectrometry; ICP-OES, inductively coupled plasma optical emission spectrometry; NR, not reported; PD, Parkinson's disease.

of 1,934 subjects consisting of 1,023 cases and 911 controls (Table 1). Meta-analysis results showed that the peripheral blood $\mathrm{Mg}$ levels of $\mathrm{PD}$ patients had a significant rising trend in random-effects model $(\mathrm{SMD}=0.64,95 \% \mathrm{CI}=0.10,1.19$; Figure 3). However, significant heterogeneity was found among these studies $\left(I^{2}=96.2 \%, P=0.000\right)$. In addition, results of subgroup analysis stratified by locations showed that compared with HC subjects, the pooled SMD was 1.78 (95\% CI $=0.70,2.86 ; P$ for $Z=0.001$ ) for Asian populations, and $1.18(95 \% \mathrm{CI}=0.80,1.55 ; P$ for $Z=0.000)$ for African populations. In addition, in stratified analysis by $\mathrm{HC}$ subjects matched by analysis methods, the pooled SMD was 1.13 (95\% CI $=0.17,2.09$; $P$ for $Z=0.021)$. However, the problem of high heterogeneity was not solved by the location or analysis method (Table 4).
Furthermore, meta-regression analyses with the covariates of duration, average age, and gender of PD patients showed that no above-mentioned covariates conferred significant impact on heterogeneity (Table 5). Sensitivity analyses indicated that none of these studies significantly reverse the result. Cumulative meta-analysis showed no temporal effect affected on the overall results. Finally, no publication bias was observed in our study, according to the Egger's tests $(P=0.324)$.

\section{Meta-analysis of CSF Mg levels between $\mathrm{PD}$ patients and $\mathrm{HC}$ subjects}

Currently, the research literature on CSF Mg levels in patients with PD is relatively less. Finally, only five articles were searched with less pooled population encompassing 


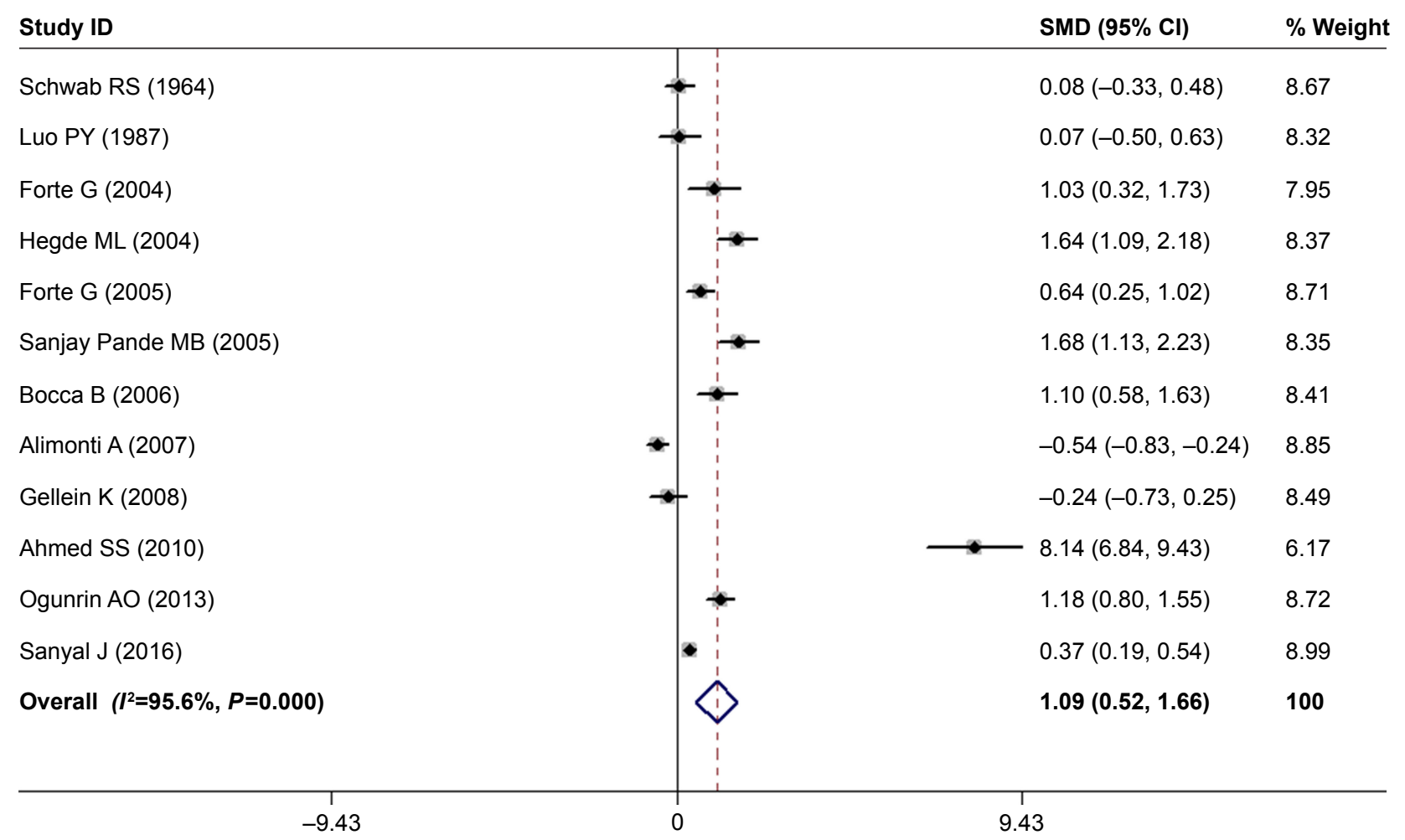

Figure 2 Forest plot of serum Mg levels between PD patients and $\mathrm{HC}$ subjects.

Notes: The horizontal lines represent $95 \% \mathrm{Cl}$. The sizes of the shaded squares are proportional to study weight. Weights are from random-effects analysis.

Abbreviations: HC, healthy control; PD, Parkinson's disease; SMD, standardized mean difference.

324 subjects composed of 180 PD cases and 144 HC subjects (Table 1). Our investigation found that PD patients had higher $\mathrm{Mg}$ levels in CSF in comparison with $\mathrm{HC}$ subjects using a random-effects model $(\mathrm{SMD}=0.55,95 \% \mathrm{CI}=0.21,0.88$; Figure 4) with moderate heterogeneity among these studies $\left(I^{2}=50.4 \%, P=0.089\right)$. Limited by fewer number of studies, no further in-depth analysis was carried out.

\section{Discussion}

To date, available literature on circulating Mg levels in PD etiology remains controversial. Thus, we aimed the previous literature comparing $\mathrm{Mg}$ concentrations in serum, peripheral blood, and CSF between PD patients and HC individuals to uncover their differences in PD. As we know, this is the first meta-analysis to quantify and report the association of

Table 2 The subgroup analysis of studies reporting serum $\mathrm{Mg}$ levels in PD

\begin{tabular}{|c|c|c|c|c|c|c|}
\hline \multirow[t]{2}{*}{ Subgroup } & \multirow{2}{*}{$\begin{array}{l}\text { No of } \\
\text { studies }\end{array}$} & \multirow[t]{2}{*}{ SMD (95\% Cl) } & \multicolumn{2}{|c|}{ Test of SMD $=0$} & \multicolumn{2}{|c|}{ Heterogeneity } \\
\hline & & & $z$ & $P$ for $Z$ & $I^{2}(\%)$ & $P$ for $I^{2}$ \\
\hline All studies & 12 & $1.09(0.52,1.66)$ & 3.76 & 0.000 & 95.6 & 0.000 \\
\hline \multicolumn{7}{|l|}{ Location } \\
\hline Asia & 5 & $2.22(0.82,3.63)$ & 3.10 & 0.002 & 97.6 & 0.000 \\
\hline Europe & 5 & $0.37(-0.32,1.06)$ & 1.06 & 0.289 & 91.6 & 0.000 \\
\hline America & 1 & $0.08(-0.33,0.48)$ & 0.38 & 0.705 & - & - \\
\hline Africa & 1 & $1.18(0.80,1.55)$ & 6.13 & 0.000 & - & - \\
\hline \multicolumn{7}{|c|}{ Analysis method } \\
\hline ICP-MS/ICP-AES & 8 & $1.55(0.54,2.57)$ & 2.99 & 0.003 & 97.0 & 0.000 \\
\hline AAS & 3 & $0.55(-0.04,1.14)$ & 1.84 & 0.066 & 88.2 & 0.000 \\
\hline Colorimetry & I & $0.08(-0.33,0.48)$ & 0.38 & 0.705 & - & - \\
\hline
\end{tabular}

Abbreviations: AAS, atomic absorption spectrometry; ICP-AES, inductively coupled plasma-atomic emission spectrometer; ICP-MS, inductively coupled plasma-mass spectrometry; PD, Parkinson's disease; SMD, standardized mean difference. 
Table 3 The meta-regression of studies reporting serum Mg levels in PD

\begin{tabular}{|c|c|c|c|c|c|}
\hline Covariates & Coefficients & $95 \% \mathrm{Cl}$ & Std. Err. & $P$-value & Adj $I^{2}(\%)$ \\
\hline Duration (years)-PD & -0.28 & $-1.00,0.43$ & 0.28 & 0.357 & -0.84 \\
\hline Mean age (years)-PD & -0.33 & $-0.83,0.17$ & 0.22 & 0.168 & 12.6 \\
\hline Female (\%)-PD & 0.04 & $-0.11,0.20$ & 2.31 & 0.530 & -7.9 \\
\hline
\end{tabular}

Abbreviations: PD, Parkinson's disease; Std. Err., standard error.

circulating $\mathrm{Mg}$ levels with PD. Herein, we found that PD patients had a higher serum Mg levels than the HC subjects ( $\mathrm{SMD}=1.09,95 \% \mathrm{CI}=0.52,1.66$ ). Furthermore, this result accorded with the combination of its serum and blood levels analysis ( $\mathrm{SMD}=0.64,95 \% \mathrm{CI}=0.10,1.19$ ). The randomeffects model was applied because of the existence of significant heterogeneity $\left(I^{2}>50 \%\right)$ among the studies. Next, we investigated the sources of heterogeneity by means of subgroup analyses and meta-regression analysis. However, above-mentioned covariates had no significant contribution to the between-study heterogeneity. The study of Ahmed and Santosh has shown a highly heterogeneous result. ${ }^{53}$ However, excluding the study, the recalculated values of $I^{2}$ in above two meta-analyses were attenuated to $91.4 \%$ and $94.4 \%$, respectively, the significant heterogeneity still existed.
This result indicated that the study of Ahmed and Santosh was not the main reason related to significant heterogeneity. A sensitivity analysis demonstrated the effect of leaving-out any individual study on the overall effect estimate each time was minimal, indicating that our findings were relatively certain and stable. The cumulative meta-analysis results were steady, suggesting the analytical instruments used for measuring serum $\mathrm{Mg}$ have become more advanced and precise in the later years. Our study suggested that the patients with PD had a tendency toward elevated circulating Mg levels, despite the high heterogeneity among studies.

$\mathrm{Mg}$ homeostasis is regulated mainly by $\mathrm{Mg}$ transporter proteins, which are located on the plasma membrane, such as TRPM6, 7 (intake) and SLC41A1 (efflux). ${ }^{37,38}$ Under normal conditions, extracellular $\mathrm{Mg}$ ions are actively transported

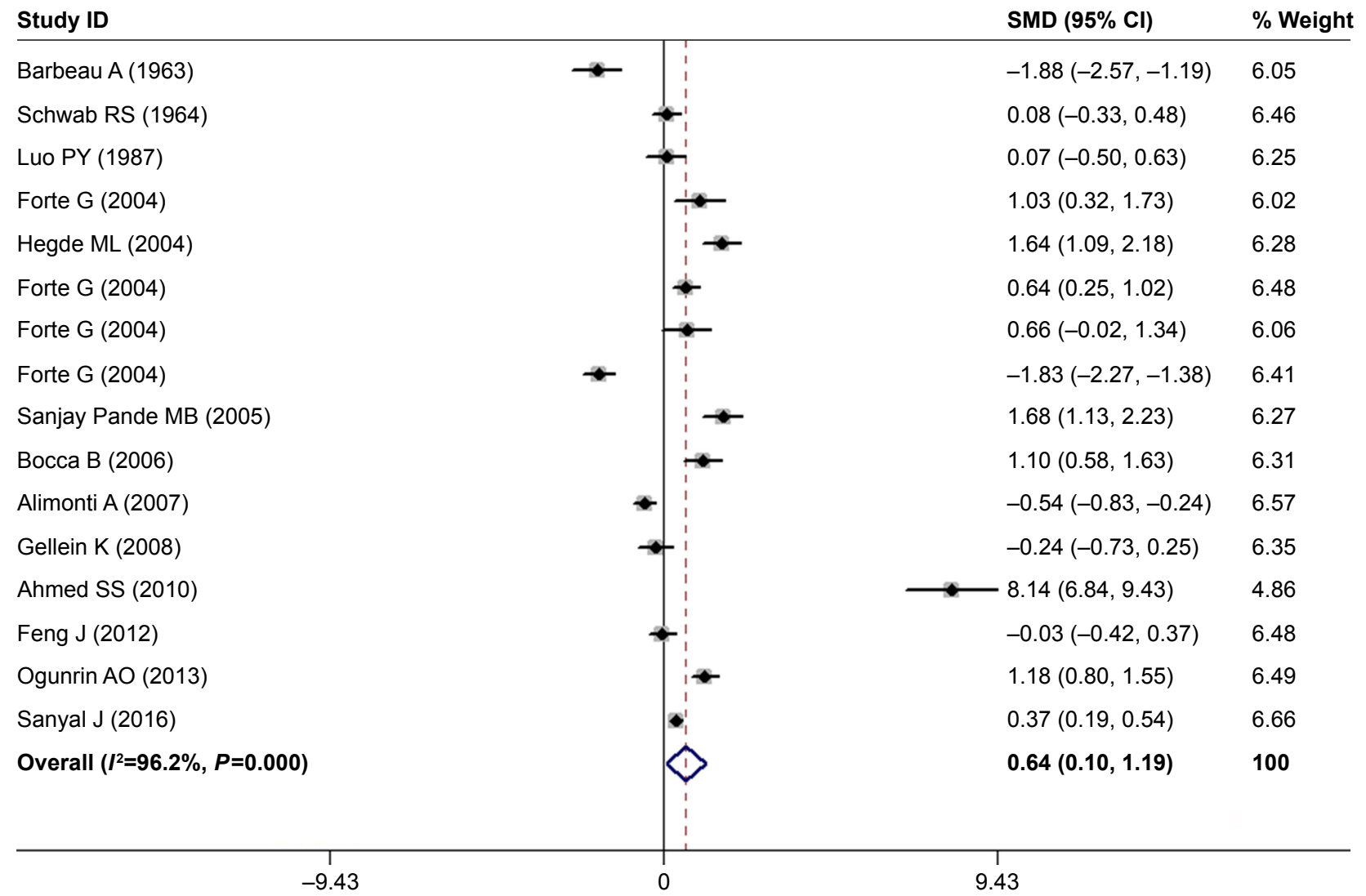

Figure 3 Forest plot of peripheral blood Mg levels between PD patients and $\mathrm{HC}$ subjects.

Notes: The horizontal lines represent $95 \% \mathrm{Cl}$. The sizes of the shaded squares are proportional to study weight. Weights are from random-effects analysis.

Abbreviations: HC, healthy control; PD, Parkinson's disease; SMD, standardized mean difference. 
Table 4 The subgroup analysis of studies reporting peripheral blood Mg levels in PD

\begin{tabular}{|c|c|c|c|c|c|c|}
\hline \multirow[t]{2}{*}{ Subgroup } & \multirow{2}{*}{$\begin{array}{l}\text { No of } \\
\text { studies }\end{array}$} & \multirow[t]{2}{*}{ SMD (95\% CI) } & \multicolumn{2}{|c|}{ Test of SMD $=0$} & \multicolumn{2}{|c|}{ Heterogeneity } \\
\hline & & & $Z$ & $P$ for $Z$ & $I^{2}(\%)$ & $P$ for $I^{2}$ \\
\hline All studies & 16 & $0.64(0.10,1.19)$ & 2.32 & 0.020 & 96.2 & 0.000 \\
\hline \multicolumn{7}{|l|}{ Location } \\
\hline Asia & 6 & $1.78(0.70,2.86)$ & 3.25 & 0.001 & 97.2 & 0.000 \\
\hline Europe & 8 & $-0.14(-0.89,0.62)$ & 0.35 & 0.724 & 94.9 & 0.000 \\
\hline America & I & $0.08(-0.33,0.48)$ & 0.38 & 0.705 & - & - \\
\hline Africa & 1 & $1.18(0.80,1.55)$ & 6.13 & 0.000 & - & - \\
\hline \multicolumn{7}{|l|}{ Analysis method } \\
\hline ICP-MS/ICP-AES & 10 & $1.13(0.17,2.09)$ & 2.30 & 0.021 & 97.3 & 0.000 \\
\hline AAS & 4 & $0.4 \mathrm{I}(-0.06,0.89)$ & 1.70 & 0.090 & 86.6 & 0.000 \\
\hline Colorimetry & 2 & $-0.08(-2.79,1.04)$ & 0.90 & 0.369 & 95.6 & 0.000 \\
\hline
\end{tabular}

Abbreviations: AAS, atomic absorption spectrometry; ICP-AES, inductively coupled plasma-atomic emission spectrometer; ICP-MS, inductively coupled plasma-mass spectrometry; PD, Parkinson's disease; SMD, standardized mean difference.

by $\mathrm{Mg}$ transporter proteins into the cell and accumulated in mitochondria. ${ }^{39}$ Thus, intracellular Mg levels are higher than those in extracellular fluid. However, many degenerative diseases including PD, often cause protein expression alterations or gene variant of these transporter proteins, thus finally lead to deranged $\mathrm{Mg}$ homeostasis. ${ }^{40}$ For example, in substantia nigra area PD patients, the mRNA and protein expression levels of TRPM7 significantly decreased, suggesting that the $\mathrm{Mg}$ influx was reduced during the progress of PD. ${ }^{41}$ Moreover, SLC41A1 is a coding region of the novel PD susceptibility locus PARK16. Its coding variant p.A350V that only occurred in the PD patients enhanced $\mathrm{Mg}$ efflux and then decreased intracellular Mg levels. ${ }^{42,43}$ Furthermore, previous clinical study also showed that due to mitochondrial cytopathies, intracellular Mg concentration in brain tissues of patients with neurologic disorders was lowered..$^{44}$ Although the reason is unknown, we hypothesized that this phenomenon might be related to $\mathrm{Mg}$ efflux from impaired mitochondria. Finally, the joint action of abovementioned various mechanisms leads to the higher Mg levels in PD patients. Consequently, we further performed metaanalysis to investigate the CSF Mg levels in PD patients. The results showed that $\mathrm{Mg}$ levels significantly increased in PD patients compared with healthy population $(\mathrm{SMD}=0.55$, $95 \% \mathrm{CI}=0.21,0.88)$. However, the limited number of studies (only five publications) and the small sample size (180 PD patients and 144 healthy individuals) conducted on CSF perhaps lead to an unreliable meta-analysis result. In CNS, $\mathrm{Mg}$ transporters across the blood-brain barrier transport $\mathrm{Mg}$ ion from blood into CSF, which create the phenomena that $\mathrm{Mg}$ levels in CSF are high like that in serum. ${ }^{45}$ Finally, peripheral high concentration of $\mathrm{Mg}$ gets into the CNS, causing CSF Mg levels rise, which could partly explain the origin of higher Mg CSF levels. In general, CSF Mg levels keep relatively steadily state even if their serum levels has been changed, thus estimating CSF Mg levels may be more precise than its blood levels. ${ }^{46}$ It was worth noting that high $\mathrm{Mg}$ CSF concentrations, in turn, accelerated the formation of $\alpha$-synuclein oligomers, both from reaction rate and from formation size, that exacerbated dopamine neurons damage and contributed to the progression of PD. ${ }^{47-49}$ For the future, continuous investigations are necessary to assess the CSF Mg levels of PD patients and expound its impact on the progression of $\mathrm{PD}$.

Nevertheless, this meta-analysis still included several limitations and shortcoming despite the strengths. First, we cited the most recent and comprehensive papers, but, the number of included studies was still limited, especially those for blood and CSF Mg levels. Future studies are necessary to confirm our conclusion with larger sample sizes. Second, we limited the search range to articles written in Chinese and English, and therefore several important papers

Table 5 The meta-regression of studies reporting peripheral blood $\mathrm{Mg}$ levels in PD

\begin{tabular}{|l|l|l|l|l|l|}
\hline Covariates & Coefficients & $\mathbf{9 5 \%} \mathbf{C l}$ & Std. Err. & P-value & Adj $\boldsymbol{I}^{\mathbf{2}}$ (\%) \\
\hline Duration (years)-PD & -0.15 & $-1.07,0.78$ & 0.39 & 0.717 & -12.9 \\
\hline Mean age (years)-PD & -0.37 & $-0.78,0.04$ & 0.19 & 0.073 & 20.3 \\
\hline Female (\%)-PD & 0.04 & $-0.07,0.15$ & 0.05 & 0.466 & -4.6 \\
\hline
\end{tabular}

Abbreviations: PD, Parkinson's disease; Std. Err., standard error. 


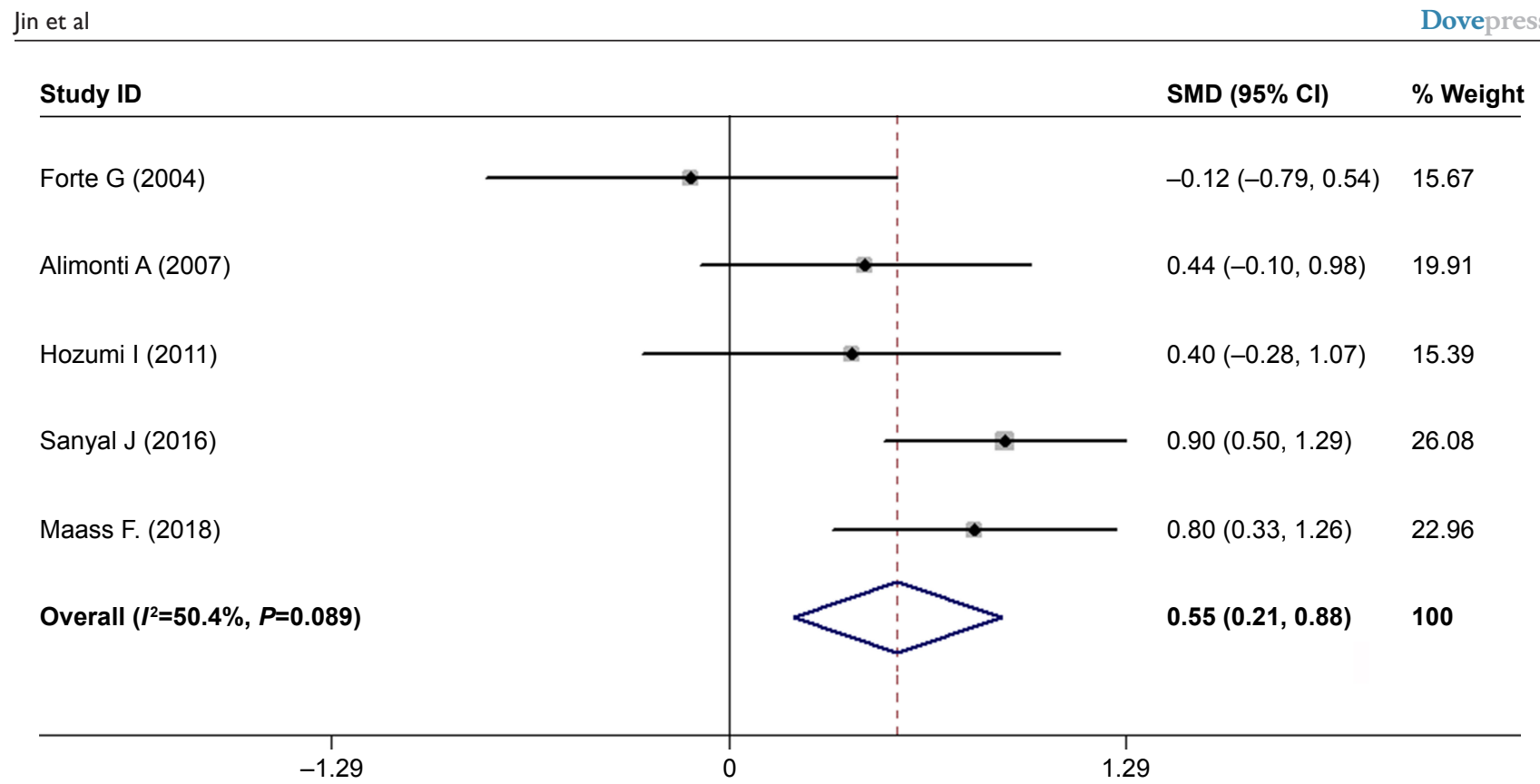

Figure 4 Forest plot of CSF Mg levels between PD patients and HC subjects.

Notes: The horizontal lines represent $95 \% \mathrm{Cl}$. The sizes of the shaded squares are proportional to study weight. Weights are from random-effects analysis. Abbreviations: CSF, cerebrospinal fluid; HC, healthy control; PD, Parkinson's disease; SMD, standardized mean difference.

published in other languages were not inevitably included. However, these cited articles probably met our inclusion criteria. Third, confounding factors, including the severity of PD, time of taking L-dopa, dietary or drug-induced $\mathrm{Mg}$ intake, socioeconomic status, and risky lifestyles (eg, alcohol, tobacco, and obesity) were difficult to collect from most of the included studies. Fourth, we only studied $\mathrm{Mg}$ levels in blood, serum, and CSF in the meta-analysis. However, most of total body $\mathrm{Mg}$ is intracellular, which makes examining $\mathrm{Mg}$ levels in erythrocytes of PD patients to comprehensively evaluate $\mathrm{Mg}$ possible implication in the pathology.

\section{Conclusion}

To our knowledge, this is the first comprehensive and systematic meta-analysis that evaluated the association between circulating Mg levels and PD patients to deeply understand the role of $\mathrm{Mg}$ homeostasis in PD. This metaanalysis emphasized that $\mathrm{Mg}$ serum, peripheral blood, and CSF levels in PD patients were obviously higher than those in healthy individuals. Due to the high heterogeneity, further investigations are needed to verify the results with large-scale cohort studies.

\section{Acknowledgments}

This work was funded by the National High Technology Research and Development Program of China (2018ZX09711001-008-006), Scientific Research Fund of Liaoning Provincial Education Department (Grant Number: LK201608), National Natural Science Foundation of China (Grant Number: 81501098, 81603112, and 81803751), Program for Liaoning Innovation Research Team in University (Grant Number: LT2014016), Key Laboratory Foundation from Shenyang S\&T Projects (Grant Number: F16-0941-00), Double Hundred Program for Shenyang Scientific and Technological Innovation Projects (Grant Number: 100040), Liaoning Province Scientific Research Foundation (Grant Number: 2014226033), and National Science and Technology Major Projects for Significant New Drugs Development (Grant Number: 2017ZX09101003-008-006).

\section{Author contributions}

All authors contributed to data analysis, drafting or revising the article, gave final approval of the version to be published, and agree to be accountable for all aspects of the work.

\section{Disclosure}

The authors report no conflicts of interest in this work.

\section{References}

1. Lees AJ, Hardy J, Revesz T. Parkinson's disease. Lancet. 2009; 373(9680):2055-2066.

2. de Lau LM, Giesbergen PC, de Rijk MC, Hofman A, Koudstaal PJ, Breteler MM. Incidence of parkinsonism and Parkinson disease in a general population: the Rotterdam Study. Neurology. 2004;63(7): $1240-1244$.

3. Sveinbjornsdottir S. The clinical symptoms of Parkinson's disease. J Neurochem. 2016;139(Suppl 1):318-324. 
4. Powers KM, Smith-Weller T, Franklin GM, Longstreth WT, Swanson PD, Checkoway H. Parkinson's disease risks associated with dietary iron, manganese, and other nutrient intakes. Neurology. 2003;60(11): 1761-1766.

5. Bettiol SS, Rose TC, Hughes CJ, Smith LA. Alcohol consumption and Parkinson's disease risk: a review of recent findings. J Parkinsons Dis. 2015;5(3):425-442.

6. Oh CK, Sultan A, Platzer J, et al. S-Nitrosylation of PINK1 attenuates PINK1/Parkin-dependent mitophagy in hiPSC-based Parkinson's disease models. Cell Rep. 2017;21(8):2171-2182.

7. Guo YB, Chen J, Zhang XD, Xu SB, Liu HY. Molecular dynamics simulations to understand LRKK2 mutations in Parkinson. Mol Simul. 2016;42(1):64-70.

8. Papagiannakis N, Koros C, Stamelou M, et al. Alpha-synuclein dimerization in erythrocytes of patients with genetic and non-genetic forms of Parkinson's Disease. Neurosci Lett. 2018;672(13):145-149.

9. Singla N, Dhawan DK. Influence of zinc on calcium-dependent signal transduction pathways during aluminium-induced neurodegeneration Mol Neurobiol. 2014;50(2):613-625.

10. Wen H, Qin Y, Zhong W, Li C, Liu X, Shen Y. Trivalent metal ions based on inorganic compounds with in vitro inhibitory activity of matrix metalloproteinase 13. Enzyme Microb Technol. 2016;92:9-17.

11. Aizenman E, Mastroberardino PG. Metals and neurodegeneration. Neurobiol Dis. 2015;81:1-3.

12. Langley MR, Ghaisas S, Ay M, et al. Manganese exposure exacerbates progressive motor deficits and neurodegeneration in the MitoPark mouse model of Parkinson's disease: relevance to gene and environment interactions in metal neurotoxicity. Neurotoxicology. 2018;64 $240-255$

13. Medeiros MS, Schumacher-Schuh A, Cardoso AM, et al. Iron and oxidative stress in Parkinson's disease: an observational study of injury biomarkers. PLoS One. 2016;11(1):e0146129.

14. Wang X, Moualla D, Wright JA, Brown DR. Copper binding regulates intracellular alpha-synuclein localisation, aggregation and toxicity. J Neurochem. 2010;113(3):704-714.

15. Li Y, Sun L, Cai T, et al. Alpha-Synuclein overexpression during manganese-induced apoptosis in SH-SY5Y neuroblastoma cells. Brain Res Bull. 2010;81(4-5):428-433.

16. Grubbs RD, Maguire ME. Magnesium as a regulatory cation: criteria and evaluation. Magnesium. 1987;6(3):113-127.

17. Laires MJ, Monteiro CP, Bicho M. Role of cellular magnesium in health and human disease. Front Biosci. 2004;9:262-276.

18. Swaminathan R. Magnesium metabolism and its disorders. Clin Biochem Rev. 2003;24(2):47-66.

19. Shindo Y, Yamanaka R, Suzuki K, Hotta K, Oka K. Intracellular magnesium level determines cell viability in the $\mathrm{MPP}^{(+)}$model of Parkinson's disease. Biochim Biophys Acta. 2015;1853(12):3182-3191.

20. Oyanagi K, Kawakami E, Kikuchi-Horie K, et al. Magnesium deficiency over generations in rats with special references to the pathogenesis of the Parkinsonism-dementia complex and amyotrophic lateral sclerosis of Guam. Neuropathology. 2006;26(2):115-128.

21. Barbeau A, Jasmin G, Duchastel Y. Biochemistry of Parkinson's disease. Neurology. 1963;13:56-58.

22. Gellein K, Syversen T, Steinnes E, et al. Trace elements in serum from patients with Parkinson's disease - a prospective case-control study: the Nord-Trøndelag Health Study (HUNT). Brain Res. 2008;1219: 111-115.

23. Alimonti A, Ristori G, Giubilei F, et al. Serum chemical elements and oxidative status in Alzheimer's disease, Parkinson disease and multiple sclerosis. Neurotoxicology. 2007;28(3):450-456.

24. Forte G, Bocca B, Senofonte O, et al. Trace and major elements in whole blood, serum, cerebrospinal fluid and urine of patients with Parkinson's disease. J Neural Transm. 2004;111(8):1031-1040.

25. Forte G, Alimonti A, Pino A, et al. Metals and oxidative stress in patients with Parkinson's disease. Ann Ist Super Sanita. 2005;41(2):189-195.

26. Bocca B, Alimonti A, Senofonte O, et al. Metal changes in CSF and peripheral compartments of parkinsonian patients. J Neurol Sci. 2006; 248(1-2):23-30.
27. Maass F, Michalke B, Leha A, et al. Elemental fingerprint as a cerebrospinal fluid biomarker for the diagnosis of Parkinson's disease. J Neurochem. 2018;145(4):342-351.

28. Schwab RS, Poryali A, Ames A. Normal serum magnesium levels in Parkinson's disease. Neurology. 1964;14:855-856.

29. Sanyal J, Ahmed SS, Ng HK, et al. Metallomic biomarkers in cerebrospinal fluid and serum in patients with Parkinson's disease in Indian population. Sci Rep. 2016;6:35097.

30. Moher D, Liberati A, Tetzlaff J, Altman DG; PRISMA Group. Preferred reporting items for systematic reviews and meta-analyses: the PRISMA statement. Int J Surg. 2010;8(5):336-341.

31. Green S, McDonald S. Cochrane Collaboration: more than systematic reviews? Intern Med J. 2005;35(1):3-5.

32. Higgins JP, Thompson SG, Deeks JJ, Altman DG. Measuring inconsistency in meta-analyses. BMJ. 2003;327(7414):557-560.

33. Song F, Gilbody S. Bias in meta-analysis detected by a simple, graphical test. Increase in studies of publication bias coincided with increasing use of meta-analysis. BMJ. 1998;316(7129):471.

34. Higgins JP, Thompson SG. Controlling the risk of spurious findings from meta-regression. Stat Med. 2004;23(11):1663-1682.

35. Tobias A. Assessing the in fluence of a single study in the meta-analysis estimate. Stata Tech Bull. 1999;8(47):15-17.

36. Duval S, Tweedie R. Trim and fill: a simple funnel-plot-based method of testing and adjusting for publication bias in meta-analysis. Biometrics. 2000;56(2):455-463.

37. Sun Y, Sukumaran P, Schaar A, Singh BB. TRPM7 and its role in neurodegenerative diseases. Channels. 2015;9(5):253-261.

38. Kolisek M, Nestler A, Vormann J, Schweigel-Röntgen M. Human gene SLC41A1 encodes for the $\mathrm{Na}+\mathrm{Mg}^{2}+$ exchanger. Am J Physiol Cell Physiol. 2012;302(1):C318-C326.

39. Kolisek M, Zsurka G, Samaj J, Weghuber J, Schweyen RJ, Schweigel M. Mrs2p is an essential component of the major electrophoretic ${ }^{\mathrm{Mg} 2+}$ influx system in mitochondria. EMBO J. 2003;22(6):1235-1244.

40. Kolisek M, Montezano AC, Sponder G, et al. PARK7/DJ-1 dysregulation by oxidative stress leads to magnesium deficiency: implications in degenerative and chronic diseases. Clin Sci. 2015;129(12):1143-1150.

41. Cook NL, van den Heuvel C, Vink R. Characterisation of TRPM channel mRNA levels in Parkinson disease. Magnes Res. 2009;22(3): 188-189.

42. Tucci A, Nalls MA, Houlden H, et al. Genetic variability at the PARK16 locus. Eur J Hum Genet. 2010;18(12):1356-1359.

43. Kolisek M, Sponder G, Mastrototaro L, et al. Substitution p.A350V in $\mathrm{Na}^{+} / \mathrm{Mg}^{2+}$ exchanger SLC41A1, potentially associated with Parkinson's disease, is a gain-of-function mutation. PLoS One. 2013;8(8):e71096.

44. Barbiroli B, Iotti S, Cortelli P, et al. Low brain intracellular free magnesium in mitochondrial cytopathies. J Cereb Blood Flow Metab. 1999; 19(5):528-532.

45. Jimerson DC, Post RM, Carman JS, et al. CSF calcium: clinical correlates in affective illness and schizophrenia. Biol Psychiatry. 1979; 14(1):37-51.

46. Levine J, Stein D, Rapoport A, Kurtzman L. High serum and cerebrospinal fluid $\mathrm{Ca} / \mathrm{Mg}$ ratio in recently hospitalized acutely depressed patients. Neuropsychobiology. 1999;39(2):63-70.

47. Hoyer W, Antony T, Cherny D, Heim G, Jovin TM, Subramaniam V. Dependence of alpha-synuclein aggregate morphology on solution conditions. J Mol Biol. 2002;322(2):383-393.

48. Lowe R, Pountney DL, Jensen PH, Gai WP, Voelcker NH. Calcium(II) selectively induces alpha-synuclein annular oligomers via interaction with the C-terminal domain. Protein Sci. 2004;13(12):3245-3252.

49. Zhang QS, Heng Y, Yuan YH, Chen NH. Pathological $\alpha$-synuclein exacerbates the progression of Parkinson's disease through microglial activation. Toxicol Lett. 2017;265:30-37.

50. Luo PY, Zhu X, Zhang YP, et al. Determination of serum trace elements levels and CT scans of brain in Parkinson's disease. Acta Univ Med Second Shanghai. 1987;7(4):332-334.

51. Hegde ML, Shanmugavelu P, Vengamma B, et al. Serum trace element levels and the complexity of inter-element relations in patients with Parkinson's disease. J Trace Elem Med Biol. 2004;18(2):163-171. 
52. Sanjay Pande MB, Nagabhushan P, Hegde ML, Rao TS, Rao KS. An algorithmic approach to understand trace elemental homeostasis in serum samples of Parkinson disease. Comput Biol Med. 2005; 35(6):475-493.

53. Ahmed SS, Santosh W. Metallomic profiling and linkage map analysis of early Parkinson's disease: a new insight to aluminum marker for the possible diagnosis. PLoS One. 2010;5(6):e11252.

54. Ogunrin AO, Komolafe MA, Sanya EO. Trace metals in patients with Parkinson's disease: a multi-center case-control study of Nigerian patients. J Neurol Epidemiol. 2013;1(1):31-38.
55. Feng J, Yang XL, Ma QP, Wang YL, Yao YN. The case-control study on relationship between blood metal elements and Parkinson disease in Uygur of Hetian region in Xinjiang. J Xinjiang Med Univ. 2012; 35(3):342-345.

56. Alimonti A, Bocca B, Pino A, Ruggieri F, Forte G, Sancesario G. Elemental profile of cerebrospinal fluid in patients with Parkinson's disease. J Trace Elem Med Biol. 2007;21(4):234-241.

57. Hozumi I, Hasegawa T, Honda A, et al. Patterns of levels of biological metals in CSF differ among neurodegenerative diseases. J Neurol Sci. 2011;303(1-2):95-99.

\section{Publish your work in this journal}

Neuropsychiatric Disease and Treatment is an international, peerreviewed journal of clinical therapeutics and pharmacology focusing on concise rapid reporting of clinical or pre-clinical studies on a range of neuropsychiatric and neurological disorders. This journal is indexed on PubMed Central, the 'PsycINFO' database and CAS, and is the official journal of The International Neuropsychiatric Association (INA). The manuscript management system is completely online and includes a very quick and fair peer-review system, which is all easy to use. Visit http://www.dovepress.com/testimonials.php to read real quotes from published authors.

Submit your manuscript here: http://www.dovepress.com/neuropsychiatric-disease-and-treatment-journal 